Revista de Estudios Histórico-Jurídicos

[Sección historia del derecho romano]

XXXVII (Valparaíso, Chile, 2015)

[pp. 93 - 107]

\title{
GUERRA Y DIPLOMACIA EN LA ROMA REPUBLICANA
}

[War and Diplomacy in the Republican Rome]

\author{
Raúl BuONO-CORE* \\ Pontificia Universidad Católica de Valparaíso
}

\begin{abstract}
RESUMEN
El artículo estudia cómo evolucionó la diplomacia romana desde la monarquía y también las peticiones de asistencia militar; y analiza las implicancias de la deditio y la capitulatio en los diversos datos que nos muestran las fuentes.

Palabras Clave

Deditio - Capitulatio - Fides - Diplomacia romana- Guerra y paz en Roma.
\end{abstract}

\section{ABSTRACT}

This article examines the way in which the Roman diplomacy evolved from monarchy and also the requests for military assistance; it also analyses the implications of the deditio and capitulatio in several pieces of information provided by the sources.

\section{KEYWORDS}

Deditio - Capitulatio - Fides - Roman diplomacy - War and peace in Rome.

Recibido el 6 de marzo y ACEPTADO el 1 de julio de 2015

* Profesor titular de historia greco-romana del Instituto de Historia de la Pontificia Universidad Católica de Valparaíso. Dirección postal: Avenida Brasil, 2650-. Casilla 4059, Valparaíso, Chile. Correo electrónico: rbuonocu@ucv.cl. Este artículo forma parte del Proyecto de Investigación Fondecyt No 1120487. 
I. El estudio de la diplomacia y la guerra en la Antigüedad, en particular en época romana, es apasionante y sobre ella hay aún mucho que decir. Con todo, me parece indispensable recordar que sobre esta temática se han publicado una infinidad de estudios sobre el asunto de la guerra y bastante menos sobre el tema de la diplomacia. En el caso de la guerra, además de artículos publicados en revistas de la especialidad, continúa siendo indispensable a pesar de sus más que dignos 40 años desde su primera edición, el libro sobre los problemas de la guerra en Roma, dirigido por Jean-Paul Brisson ${ }^{1}$, en mi opinión, una de las más precisas y rigurosas síntesis sobre el problema; sin embargo se deben revisar también las últimas contribuciones de Arthur M. Eckstein ${ }^{2}$ y de W. V. Harris ${ }^{3}$. Sobre la diplomacia romana, se han publicado algunos libros de autoría personal y otros con diversos contenidos pero de carácter colectivo. En primer lugar sobre la diplomacia romana el libro de Claudine Auliard ${ }^{4}$ me parece de lo más completo escrito desde hace mucho tiempo; dentro de las obras colectivas, sobre el problema de la guerra y la diplomacia, el reciente libro dirigido por Emmanuèle Caire y Sylvie Pittia ${ }^{5}$ me parece una de las más logradas. Son además una contribución destacable los libros dirigidos por Claude Eilers, Ed. Frézouls y A. Jacquemin ${ }^{6}$, que incluyen estudios de diversos períodos de la historia romana.

No se debe olvidar que para cualquier análisis de la diplomacia romana, se debe considerar que muchos aspectos de ésta, son consecuencia del legado que los griegos le dejaron a Roma, sobre todo en los primeros tiempos, período en el cual se fueron elaborando muchas de sus particulares características, de las cuales un número destacado se mantienen hasta nuestros días. Esto último, no deja de ser sorprendente que sea sistemáticamente ignorado o quizás, desconocido por historiadores o analistas de la diplomacia moderna de la importancia de un Harold Nicholson ${ }^{7}$, como se sabe, lectura obligada en todas las academias diplomáticas del orbe, quien al referirse brevemente a la antigüedad, en particular a Roma, afirma que "los romanos no estaban especialmente dotados para el arte de la negociación y durante los múltiples siglos de su supremacía, sus métodos fueron los del legionario y el constructor de carreteras más bien que el de un diplomático"

\footnotetext{
${ }^{1}$ Brisson, J.-P., Problèmes de la guerre à Rome (Paris, 1969).

${ }^{2}$ Especialmente: ECKSTEIN, A. M., Mediterranean Anarchy, Interstate War, and the Rise of Rome (Berkeley - Los Angeles - London, University of California Press, 2006).

${ }^{3}$ Harris, W. V., War and Imperialism in Republican Rome 327-70 B.C. (Oxford, 1979; traducción al castellano, Madrid, 1989).

${ }^{4}$ Auliard, C., La diplomatie romaine. L'autre instrument de la conquête. De la fondation à la fin des guerres samnites (753-290 av. J.-C.) (Rennes, 2006).

${ }^{5}$ Caire, E. - PitTiA, S. (editores), Guerre et diplomatie romaines, IV-III siècles av. J.-C., pour un réexamen des sources (Aix-en-Provence, 2006).

${ }^{6}$ EILERS, C. (editor), Diplomats and Diplomacy in the Roman World (Leiden - Boston, Brill, 2009); y Frézouls, Ed. - JaCQuemin, A. (editores), Les relations internationales. Actes du Colloque de Strasbourg 15-17 juin 1993 (París, De Boccard, 1995).

${ }^{7} \mathrm{Si}$ se piensa que el mencionado manual ha sido leído por cientos de diplomáticos por decenios hasta la actualidad, la magnitud del daño hecho a un adecuado conocimiento de la historia de la diplomacia occidental es inconmensurable: Nicolson, H., Diplomacy (London, Oxford University Press, 1939; traducción al castellano, México, Fondo de Cultura Económica, 1948).

${ }^{8}$ Ibíd., p. 27
} 
continúa afirmando que "En el peor de los casos eran implacables en sus objetivos y brutales en sus métodos. En el mejor desarrollaban el principio de aplastar a sus contrincantes más obstinados y perdonar a los sumisos”. Por último, demostrando algún arrepentimiento por lo dicho anteriormente, sostiene que la "contribución romana a la diplomacia no debe buscarse en el campo de la negociación sino en

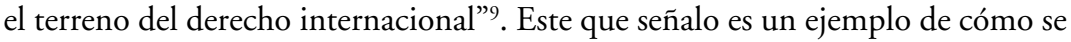
ha tejido el estigma que presenta al mundo romano como una sociedad alejada de la paz, desconociéndose que el instrumento de la diplomacia fue aplicado en Roma desde la monarquía con el fin de evitar guerras y conflictos, aunque por cierto, en la mayoría de los casos las iniciativas diplomáticas no tuvieron éxito ${ }^{10}$.

II. La evolución en el uso de la diplomacia en el período de los reyes de Roma, y los importantes cambios en su contenido, la transforman en un instrumento sumamente frecuente. Si se revisan la fuentes para el período que va desde la expulsión de los Tarquinios hasta la toma de Veyes (509-396), estas entregan datos de aproximadamente 135 acciones diplomáticas, lo que representa una cantidad muy superior a las que encontramos durante la monarquía. Las relaciones con los pueblos de Italia central son en general bastante agresivas, lo que se traduce en numerosas acciones diplomáticas que llevan implícitas intenciones bélicas. Veinte de estas embajadas que en el siglo $\mathrm{V}$ representan aproximadamente el 15\%, presentan un ultimátum, amenazas o reclamos. Ciertamente que es un período durante el cual, la guerra se asoma abiertamente como un elemento a considerar en labores de esta índole. A diferencia de las negociaciones comerciales llevadas a cabo por algunas embajadas, estas en cambio no dan pie para algún tipo de negociación. Parece claro que el objetivo fue y continua siendo el evitar la guerra, pero casi todas las legaciones tuvieron un resultado negativo y van seguidas de un abierto conflicto. Estas misiones, por lo tanto, hay que situarlas entre una declaración de guerra y la práctica diplomática, por lo que tampoco son comparables a la labor de los Fetiales, oficialmente vinculados al ámbito religioso y sin la intención de evitar las guerras. La finalidad un tanto ambigua de estas misiones, explica por qué

${ }^{9}$ Ibíd., p. 27.

${ }^{10}$ BuOnO-Core, R., Diplomacia y monarquía. Rómulo y Numa, en REHJ., 25 (2013), pp. 111-130. Para este período conviene tener a la vista además: GABBA, E., Considerazione sulla tradizione letteraria sulle origini della repubblica, en Les origines de la République Romaine, Entretiens Hardt, XIII (Genève, 1967), pp. 137 ss.; CORNELL, T., Alcune riflessioni sulla formazione della tradizione storiografica su Roma arcaica, en Roma arcaica e le resentí scoperte archeologique. Giornate di studio in onore di U. Coli. Firenze, 29-30 Maggio 1979 (Milano, 1980), pp. 19 ss.; Ampolo, C., La storiografia su Roma arcaica e $i$ documenti, en Tria Corda. Studi in onore di Arnaldo Momigliano (Como, 1983), pp. 9 ss. Ampolo, C. y otros, Popoli e civiltà dell Italia antica (Roma, 1984), VIII, pp. 379 ss.; POUCET, J., Les origines de Rome (Bruxelles, 1985); El MISMO, Les Rois de Rome Tradition et histoire (Bruxelles, 2000); GABBA, E., Ancora sulle origini di Roma, en Athenaeum, 89 (2001), pp. 589-591; CoRnELl, T. J., The Formation of the Historical Tradition of Early Rome, en Moxon, I. - Smart, J. D. - Woodman, A. J. (editores), Past perspectives: Studies in Greek and Roman Historical Writing (Cambridge, 1986), pp. 67 ss.; LETTA, C., La tradizione storiografica sull età regia: Origine e valore, en Alle Origini di Roma. Atti del Colloquio tenuto a Pisa il 18 e 19 settembre 1987 (Pisa, Giardini, 1988), pp. 61 ss.; GrandazzI, A., La fondation de Rome (Paris, 1991); Carandini, A., La nascità di Roma (Torino, 1997); y Auliard, C., La diplomatie romaine (Rennes, 2006), sobre todo la primera parte. 
un número considerable de conflictos, probablemente no fueron informados ni hay tampoco antecedentes de acciones diplomáticas previas. Las intervenciones de los Fetiales durante el siglo $\mathrm{V}$ a. C. son raras las veces mencionadas en las fuentes; entre los casos más destacables está el del 488 a. C., cuando son enviados donde los Coriolanos ${ }^{11}$; el 466 y 458 donde los ecuos ${ }^{12}$, y en el 427 y 407 donde Veyes ${ }^{13}$. Sin embargo se debe tener presente que en la mayoría de los casos son enviados después del fracaso de las misiones llevadas a cabo por otros intermediarios.

III. Entre el 509 y el 477 a. C. las fuentes contienen datos sobre una serie de reclamos y declaraciones de guerra presentados por ciudades y pueblos contra Roma. Vemos ocho embajadas seguidas en Roma: la de los Tarquinios el 509 ${ }^{14}$, la de los Sabinos el $503^{15}$, la de los Latinos el 500 y el $498^{16}$, la de los Auruncos y de los Volscos después de la batalla del lago Regulo, en los años 495, 494 y $489^{17}$, y la de Veyes el $477^{18}$.

Todas las reclamaciones o solicitudes de reparaciones formuladas contra Roma, todas con la excepción del reclamo de los Tarquinios el 509 a. C., conducen rápidamente a guerras. En el mismo lapso de tiempo, los romanos son capaces de llevar a cabo cuatro iniciativas similares: dos antes del foedus cassianum, contra los Sabinos el $505^{19}$, y contra los Latinos el $501^{20}$; y dos después del tratado con los Volscos de Antium el 491 21 y los Hérnicos el $487^{22}$. Como se comprenderá, este es un período de grandes tensiones, más bien de acción y reacción, en el cual las ciudades hacen grandes esfuerzos por vivir en paz, pero manteniendo sus áreas de influencia, lo que le dificulta a Roma sus afanes hegemónicos. Una prueba de esto, es su rol ante la asamblea general de todas las ciudades latinas que se habían confabulado contra Roma para desencadenar una guerra, el cónsul Marco Valerio intenta en vano imponerse, para renunciar finalmente a cualquier reacción.

IV. La realidad de la presión sobre Roma durante los primeros años de la República se expresa bajo la forma de amenazas a su pueblo. Hay momentos en que toda conciliación parece imposible. En efecto, según la tradición, la evidente agresividad de sus enemigos, obligan a Roma a iniciar casi siempre las hostilidades. Sin embargo en otras circunstancias, Roma no aplicará los mismos esquemas a los que son sus enemigos. Por ejemplo, el 468 y 454 la ciudad parece querer ex-

${ }^{11}$ App., It., 5, 1-2; Liv. II,39,9-12; Dion. Hal.VIII,37,1-3; Plutarch., Cor., 30-31; Val. Max. V,4,1.

${ }^{12}$ Dion. Hal. IX,60,3-6.

${ }^{13}$ Liv. IV,30,13-15; IV,58,1-2.

${ }^{14}$ Plutarch., Publ., 2, 3-4; 3, 1; Dion. Hal. V, 4-5; Zon., 7,12; Liv., II,3-4; Dion. Hal. V,6.

${ }^{15}$ Dion. Hal. V, 45,1-3.

${ }^{16}$ Dion. Hal. V, 52, 5; V,61,4-62, 1 ; Ет. 54,4-5;

${ }^{17}$ Liv. II,26,4-6; Dion. Hal. VI,32,1-3; VI,34,4-37,1; VIII,68,2; PlutarCh., Cor., 39, 13.

${ }^{18}$ DiOn. HAL. IX, 18,4 .

${ }^{19}$ Dion. Hal. V,37,2-3.

${ }^{20}$ Dion. Hal.V, 50,3-51,2.

${ }^{21}$ Dion. Hal. VII,37, 5; Plutarch., Cor., 26, 2.

${ }^{22}$ Dion. Hal. VIII,64,1-2. 
tremar las precauciones en particular, durante los conflictos contra los Ecuos ${ }^{23}$. Se declara la guerra o se hacen reclamaciones de restitución en cinco ocasiones, en menos de 15 años. Hay que considerar también que de alguna manera, esta puede ser considerada una consecuencia del conflicto patricio plebeyo y el período decenviral, que deja a Roma más expuesta. Permanentemente la tradición establece un estrecho vínculo entre las decisiones en materia de política exterior y las de política interna.

En la antigüedad como en los primeros milenios de nuestra era, el derecho diplomático no se preocupa de separar con claridad el estado de guerra del estado de paz. Su papel está en poner en evidencia no solo el estado de guerra sino los argumentos del contrario, en términos de los golpes o daños recibidos de parte del adversario, que legitimarán una reacción, realidad que siempre tendrá relación con el principio del derecho del más fuerte. El derecho diplomático concibe el ius in bello como el sometimiento total del vencido a los derechos del vencedor.

Pero esta tradición no es solo romana, sino que forman parte de una realidad más amplia, de carácter al menos mediterráneo. En los primeros milenios de nuestra era, las relaciones entre los grupos humanos fueron esencialmente conflictivas, y los recursos empleados privilegiaron los enfrentamientos armados, convirtiéndose en una constante o en algo permanente en la historia de esas relaciones. El uso de la violencia entre las diversas comunidades humanas, ha quedado registrado en sus diversos aspectos por los autores antiguos, pudiéndose advertir que como consecuencia de esto, dejó en algún momento, un espacio para lo que hoy llamamos la diplomacia o la ciencia de los intereses y relaciones de unos Estados con otros. En un mundo donde las diferentes formas de enfrentamiento son sistemáticamente valoradas, donde la legitimidad de la guerra se afirma a través del prestigio individual y colectivo de la victoria. ¿Qué lugar se le puede reservar entonces a la diplomacia?

$\mathrm{V}$. Como en el mundo griego, en Roma se reconoce la existencia del derecho de la gente, un argumento del que hacen uso los vencidos en nombre de una humanidad ultrajada por los conflictos bélicos. Las naciones entonces se compenetran de ideas que permiten hacer entender que para la guerra y la violencia, no hay más límites que la clemencia y la magnanimidad de los vencedores.

Las evidencias nos permiten pensar que en Roma existieron contactos paralelos o complementarios junto a los conflictos armados, aun cuando las formas de contactarse en los primeros siglos de la historia romana fueron necesariamente rudimentarios y básicos, pero que con el paso del tiempo se fueron puliendo y perfeccionando, en la medida que como resultado de las conquistas, las instituciones romanas también lo fueron haciendo. Así entonces, los fundamentos y normas de la diplomacia comenzaron a enriquecerse, haciéndose más sólidos, advirtiéndose un progreso que se puede constatar en la medida que mejoraba la calidad de la cultura y de los responsables de la política. Este fue un proceso sumatorio y acu-

${ }^{23}$ Dion. Hal. IX,59,3-4, 5; Liv. III,1,8. 
mulativo, algo que estuvo al parecer, en la naturaleza y en la mentalidad romana desde la época más primigenia ${ }^{24}$.

VI. Otro aspecto lo constituyen las propuestas o peticiones de asistencia militar, las que sin lugar a dudas, formaron parte de la esfera de la diplomacia, porque estaban estrechamente relacionadas con la naturaleza de los contactos que Roma estableció con aquellos que las formulaban, o a quienes iban dirigidas. Dado que la terminología utilizada por algunos autores antiguos a veces nos confunden por su falta de precisión en la aplicación de enfoques de naturaleza aparentemente muy diferentes, algunos estudiosos como Francesco de Martino, han considerado por ejemplo, que la deditio es asimilable a una capitulación ${ }^{25}$. Se entiende como un acuerdo bélico formal, por el que ambas partes estipulan conjuntamente condiciones que van a regular la situación futura de personas o cosas entre los contendientes. Es un convenio cerrado mediante solemnes libaciones que ambos bandos se comprometen a respetar a través de un juramento ligando al vencedor con el vencido.

a) Recordemos que la deditio consiste antes que nada, en la sumisión de un pueblo extranjero al Estado romano a través de algo similar a un contrato verbal ${ }^{26}$. El formulario estaba constituido por preguntas y respuestas de las dos partes; un ejemplo nos lo entrega Tito Livio, quien da la noticia que en ocasión de una guerra contra los latinos y sabinos, el rey de Roma pregunta: [“ $¿$ Sois vosotros los representantes y portavoces enviados por el pueblo colatino?" "Sî". "El pueblo colatino, ¿es libre para disponer de su destino?” "Sî”. “¿Os entregáis, a vosotros y al pueblo colatino, ciudad, campos, agua, límites, templos, bienes muebles, bienes todos sagrados y profanos, a mi poder y al del pueblo romano?" "Sî". "Y yo os recibo" $\left.{ }^{27}\right]$.

Esto refuerza la idea que la deditio es la sumisión total al poder soberano del vencedor, del cual ya no era posible liberarse. La deditio puede tener como causa la rendición del enemigo, que fue la causa más corriente, pero también puede ocurrir sin haber una guerra como antecedente. Sus efectos jurídicos consisten en la transferencia al poder de Roma, de todos los elementos jurídicos de la soberanía y de la colectividad política.

Era por lo tanto el Estado romano el que decidía en qué medida el pueblo sometido podía conservar su autonomía, o bien, era disuelto o mantenido en condiciones de una libertad relativa, hasta ser inscrito en una tribu romana. Además, el pueblo que estaba en esa condición, podía ser organizado como municipio romano, e incluso como un municipio federado. Estas distintas soluciones eran posibles gracias a la potestad del pueblo romano. Por esto, desde un punto de vista jurídico, la deditio no significaba en sí misma la extinción de la comunidad,

\footnotetext{
${ }^{24}$ Sobre estas ideas ver la obra de De Francisci, P., Primordia civitatis (Roma, 1959); EL MISMO, Variación su tempi di Prehistoria Romana (Roma, 1974); y HerRERA, H., Res privata, res publica, imperium, en Semanas de Estudios Romanos (Valparaíso 1977), I, pp. 128-136.

${ }^{25}$ De Martino, F., Storia della costituzione Romana (Napoli, 1964), II, p. 47 ss.

${ }^{26}$ Ibíd., p. 47 y ss.

${ }^{27}$ LIV. I,38,2.
} 
sino la transferencia del poder, y la disposición de un modo absoluto, de todos los elementos jurídicos y materiales. Dicho de otro modo, el pueblo, que estaba bajo la condición de deditio, (adicto), se ponía bajo el poder de Roma, por lo tanto, no solo se traspasaba la soberanía, sino que esto incluía también la tierra y las personas. Con la deditio por ejemplo, se podía imponer ciertas condiciones tales como la entrega de las armas y de los generales enemigos antes de su implementación. Otras disposiciones, como la entrega de rehenes y el pago de los costos de la guerra ${ }^{28}$, podían ser incluidas en el tratado y se hacían efectivas después que este se ratificaba.

b) Es necesario separar del ámbito de la diplomacia las deditiones individuales que caen en realidad, en una forma de capitulación, permitiendo que sólo unos pocos soldados en dificultad, salven sus vidas ${ }^{29}$. Sin embargo, las deditiones colectivas, aplicadas por los funcionarios oficiales del poder de una ciudad o un pueblo, deben en mi opinión, ser asimilados como esfuerzos de tipo diplomático. El procedimiento, que se ha certificado por diversas narraciones, hace que sea posible establecer con claridad las diferencias entre capitulatio y deditio.

c) En segundo lugar, una deditio puede ser aceptada, (lo que es el escenario más común), o bien rechazada por Roma, pero también por el enemigo. Sobre esto doy dos ejemplos: El 341 a. C., los sedicinos comenzaron haciendo una deditio con los romanos, pero como el Senado rechazó dicho acto, finalmente, y arrastrados por una extrema necesidad, se sometieron a los latinos ${ }^{30}$. En el sentido contrario, está la deditio propuesta que puede ser rechazada: por ejemplo, Jugurta en el 109 a. C., rechaza la propuesta hecha por el cónsul Metelo ${ }^{31}$. Sin embargo, en el contexto de una capitulación, no hay rastros de alguna forma de contacto, de algún debate o de algún tema a discutir entre el vencedor y el vencido; el derecho del vencedor se ejerce en todos los ámbitos, prohibiendo a los vencidos pensar en su futuro.

d) En tercer lugar, las diferencias entre deditio y capitulatio sobre la base de fórmulas, diferenciadas por la mayoría de nuestras fuentes: "venire in fidem" (llegar confiando) no debe confundirse con la fórmula "venire in potestatem" (llegar en propiedad). El 214 a. C., el pontífice Papirius recuerda al cónsul Q. Lutatius, que no puede cometer abusos contra la ciudad de los falerios porque esta no se entregó a la potestad, sino a la fe (confianza) de los romanos ${ }^{32}$. Esta distinción le prohíbe al pontífice el saqueo de la ciudad y la masacre de la población. Si las garantías ofrecidas por las deditio están contractualmente establecidas y aceptadas implícitamente por ambas partes, se puede evitar el saqueo de la ciudad y los abusos contra sus habitantes. Las mínimas garantías de una deditio son confirmadas también por las reacciones negativas de los soldados romanos, quienes ante una deditio, se ven privados del botín. Vemos entonces, que los beneficios de la deditio

${ }^{28}$ LIV. V,27,14; V,27,15; IX,20,4; XXII,20,11; XXVIII,34,7; XXIX,3,5; XXIX,3,15; DiOD. Sic. XIX,10,2; Polib., XXXVI,5,6; CAesar, De bello Gall., VI,9,6; Dio. Cass., VIII,68,2; IX,58,8.

${ }^{29}$ LIV. II,30,15. Se refiere a la deditio individual de algunos volscos en el curso de un combate el 494 a. C., la que no se puede considerar un acto diplomático.

${ }^{30}$ LIV. VIII,2,6.

${ }^{31}$ Sallust., Iug. 62.

${ }^{32}$ VAL. MAX. VI,5,1: “dedisse se prius in fidem, quam in potestatem, populi romani”. 
son considerables. Pueden ser aceptados, rechazados e incluso renegociados; esto permite la preservación e integridad demográfica, junto al potencial económico de una ciudad.

En mi opinión, de acuerdo al funcionamiento de las instituciones, hay una ventaja decisiva: en efecto, las disposiciones de una deditio son establecidas por el jefe del ejército, sin la necesidad de la ratificación del pueblo. No es necesario realizar una votación en las asambleas o enviar una comisión del Senado para establecer las condiciones de las relaciones futuras entre el pueblo o la ciudad implicada y Roma. El procedimiento es tan flexible que permite muchos cambios posteriores, en función de la evolución de la situación y de la voluntad de Roma. Esta muy especial forma de la práctica diplomática romana, debe ser aún analizada con mayor atención, porque su evolución inexorablemente conduce a otras formas de la diplomacia, que se convertirán posteriormente, en la base general de las relaciones internacionales.

VII. Si al comienzo, las diferencias entre deditio y capitulatio parecen muy tenues y poco visibles, la evolución fácilmente perceptible del uso de estas palabras, nos permite hacer una distinción lo suficientemente clara como para permitir la inserción del análisis de las deditiones en el campo diplomático. Ello constituye probablemente uno de los aspectos más creativos de la diplomacia romana, diplomacia que antes que nada, parecía caracterizarse por un gran pragmatismo y por un sentido práctico en la solución de las controversias.

También hay que recordar que hubo un total monopolio ejercido por el Senado, el que como es sabido, fue un baluarte del poder del patriciado, hecho que determinará la conducción de la política exterior. Por esto, todos los Estados se dirigieron a ese organismo para entrar en relación con Roma. El Senado no le entregaba a los jefes militares las facultades para declarar una guerra, por el contrario, una guerra no se podía declarar sin una ley votada por los comicios centuriados ${ }^{33}$; pero sabemos que por las características de su organización y los procedimientos seguidos, los electores dependerán significativamente de la aristocracia senatorial ${ }^{34}$. Pertenecían a esta aristocracia los magistrados responsables de la dirección de las operaciones o de las relaciones con los extranjeros, como los cónsules o pretores encargados de la conducción de los ejércitos y de la administración de las provincias. Su actividad diplomática, al igual que la organización de los territorios sometidos o conquistados, estaba bajo la vigilancia de comisiones constituidas por el Senado dentro de su propio seno, lo que como G. Clemente ha demostrado, va creando agrupaciones de verdaderos diplomáticos con especialización en diversos temas relacionados con las relaciones exteriores ${ }^{35}$. Se entiende que la carrera política de estas personas, así como sus medios de acción, dependían del apoyo que encontraban en la asamblea senatorial.

\footnotetext{
${ }^{33}$ LIV. XXXV,6.
}

${ }^{34}$ Cary, M. - Scullard, H. H., A History of Rome (London, McMillan, 1973; traducción al italiano, Bolonia, 1981), I, p. 135.

${ }^{35}$ Clemente, G., Esperti ambasciatori del senato e la formazione della politica estera romana tra il III e il II sec. A. C., en Athenaeum, N.S., 64 (1976), pp. 293-213. 
VIII. Cuando pueblos como los galos asolan en el siglo IV a. C. el territorio cercano a Roma, impresionan de tal modo a sus habitantes, que ante la inminente llegada de estos, se decreta el reclutamiento masivo. En cada ocasión de estas características, debemos entender que además se producía un enfrentamiento entre la civilización de la ciudad, sólidamente implantada alrededor de su foro y de sus templos, y la de los pueblos que permanecían en un estado de bandas casi sin organizar y constantemente empujadas fuera de un hábitat más o menos permanente, por necesidades económicas o demográficas, pueblos con los que Roma interactuará permanentemente durante sus conquistas. Una de las consecuencias de que los galos carecieran de un sentido urbano es que los alejaba de los aspectos jurídicos que envolvían los conflictos bélicos y diplomáticos.

Polibio nos entrega la información del momento en que en el siglo III a. C., Mario Curio Dentato envía mensajeros al territorio galo para tratar asuntos concernientes a la devolución de prisioneros, consecuencia de la derrota que el ejército del cónsul Lucio Cecilio Metelo había sufrido. El resultado de esta acción diplomática será que los galos despreciando el ius gentium, que protegía a los legados, los asesinaron. En un caso como este, se produce una abierta confrontación entre los principios que sustentan la civilidad y el mundo extra urbano e irracional representado por los galos. La actitud de estos últimos enfurece a Roma, lo que finalmente trae como consecuencia una campaña militar contra los galos senones a quienes vencen, fundándose Sena, la primera colonia romana en la Galia ${ }^{36}$.

Ante de ser capaz de concebir y asumir esta misión, Roma tuvo que habituarse a descubrir y palpar los peligros que la amenazaban, más allá del contacto inmediato con el enemigo. Además, tuvo que sufrir un largo aprendizaje en el terreno de la actividad diplomática, permitiéndole adquirir tempranamente la capacidad necesaria para reflexionar en cuanto a las implicaciones, aunque estuviesen alejadas de sus decisiones. Los romanos que habían combatido contra los galos en el siglo IV a. C., cerca de la ciudad, o de los montes albanos, probablemente ignoraban que estas bandas errantes, empujadas por necesidades materiales, al parecer eran utilizadas por Dionisio, tirano de Siracusa, para debilitar a sus adversarios en la península itálica.

Cuenta la tradición, que una premonición de la llegada de los galos la tuvo el plebeyo M. Caedicius, bajo la forma de una voz, pero los magistrados no le creyeron. Poco después llegó una solicitud de ayuda contra los galos de la ciudad etrusca de Chiusi, quienes instalados por más de dos siglos en el valle del Po, se habían cautivado al parecer, con las bondades del vino producido en Etruria, del cual en parte al menos, fue responsable del ataque un personaje de nombre Arrunte, quien estaba molesto con el Lucumón, del cual había sido su tutor, porque este que había seducido a su esposa, debido a su alta posición, solo podía castigarlo buscando ayuda externa ${ }^{37}$. Cuando los habitantes de Chiusi pidieron ayuda a Roma, tenían a su favor las buenas relaciones obtenidas en la época de Porsena, rey de la ciudad, y sobre todo, la posición neutral que mantuvieron en

\footnotetext{
${ }^{36}$ Para el problema de la colonización resulta fundamental LAFFI, U., Colonie e municipi nello Stato romano (Roma, 2007).

${ }^{37}$ Liv. V,33; App., Celt. II,1; Dio. Cass. VII,25,1; Plutarch., Camilus, 17,1.
} 
el conflicto con Veyes, ocurrido poco tiempo antes. Frente a esta situación, el Senado responde enviando una legación que estaba integrada por los tres hijos de M. Fabius Ambustus. Cuando los legados romanos se presentan ante los jefes galos, estos creen que ya tienen derechos adquiridos sobre una parte del territorio que según ellos, Chiusi tenía abandonado, derechos que bajo otras circunstancias, seguramente habrían usado las armas para hacerlos prevalecer ante la presencia de los legados romanos.

IX. Sabemos que las ciudades instaladas en el Lacio estaban agrupadas en una confederación de carácter religioso, la Liga Latina, cuyos miembros mantenían complejas relaciones entre sí. Roma participó en esa alianza intensamente, del mismo modo que en las rivalidades políticas que los enfrentaba ${ }^{38}$. Luchó contra las invasiones de los pueblos vecinos de esta Liga, ayudándolos a instalar colonias militares para mantenerlos alejados, cuya creación la tradición la atribuye exclusivamente a los romanos, basándose en una inmediata sumisión a Roma, junto con las ciudades confederadas de quien adoptaron el sistema de implantación sobre un territorio conquistado. El resultado fue que se habituaron a prever los peligros que les amenazaban más allá de los límites de sus tierras.

Es así como paso a paso, los romanos pusieron a punto y practicaron con mayor facilidad cada vez más, el sistema de estricta restricción que para ellos representaba la fides, la buena fe, base de sus relaciones con los extranjeros y con sus propios ciudadanos, concepto cuya importancia política, religiosa y social, ha sido demostrada ampliamente y cuya importancia se prolonga durante todo el período republicano ${ }^{39}$. Se trata con mayor razón de algo más que una "piadosa ficción" cuando invoca el 343 a. C. para justificar la primera guerra samnita; Capua se había "ofrecido" tanto a Roma, que la obligaba a defenderla contra los samnitas aliados de Roma. Hechos como este, van a producir una cadena de acontecimientos en esa dirección.

X. Historiadores como E. Badian, consideran que la mayoría de las expediciones posteriores, que conducirán a la conquista del sur de Italia y de Sicilia, se planificaron en las mismas condiciones ${ }^{40}$. El 329 a. C. otras ciudades de la Campania reclaman la ayuda de Roma contra los samnitas ${ }^{41}$; el 322 a. C. lo hacen también Luceria y Arpi, amenazadas por los montañeses ávidos de los espacios que ofrecía la llanura apuliana a lo largo del Adriático. La tercera guerra samnita el año 299 a. C., es causada por la petición de auxilio por parte de los lucanos, después de concluir un tratado con ello ${ }^{42}$. Cada progreso de Roma en Italia, aumenta sus responsabilidades, convirtiéndola en la potencia más idónea para

\footnotetext{
${ }^{38}$ Heurgon, J., La guerre romaine aux IV-III siècles et la "fides romana", en Problèmes de la guerre à Rome (Paris, 1969), pp. 23-32; Clemente, G., Dal territorio della città all egemonia in Italia, en Storia di Roma, II,1: La repubblica imperiale (Torino, Einaudi, 1990), pp. 19-38.

${ }^{39}$ Catalano, F., Linee del sistema sovranazionale romano (Torino, 1966), I.

${ }^{40}$ Badian, E., Foreign Clientelae (264-70 a. C.) (Oxford, 1958), pp. 30-35.

${ }^{41}$ LIV. VIII, 19 .

${ }^{42}$ Liv. X,11,9-12,2; Dion. Hal. XVI,11,1.
} 
proteger el mundo de las ciudades, un mundo demasiado dividido para ser sólido contra las oleadas procedentes de los pueblos montañeses. La ganada reputación de la palabra de Roma motiva a esas ciudades a pedirle ayuda y a celebrar esta fides para comprometerla ${ }^{43}$.

Un mecanismo muy similar lo encontramos en el origen de las guerras púnicas, especialmente en las dos primeras, resultado de una conducta, más que de una iniciativa consciente. El 306 a. C., Roma renueva su tratado con Cartago y reconoce su derecho a ejercer un monopolio en Sicilia ${ }^{44}$. El 264 a. C. Roma interviene en Sicilia y dos años más tarde, ataca la ciudad de Agrigento, cabeza de puente cartaginés ${ }^{45}$. El conflicto tiene lugar en dos etapas. En un principio Roma fue reclamada junto con sus aliados cartagineses por los habitantes de Mesina, antiguos mercenarios campanienses de Agátocles, tirano de Siracusa.

Gerón, responsable del desmantelamiento de la democracia establecida por este último antes de su muerte, intentaba desde hace algún tiempo recobrar sus territorios. Derrotado en Mesina, y luego en Siracusa, se somete a los romanos llevándoles a su vez, en el año 262 a. C. a una guerra contra Agrigento.

El segundo conflicto con Cartago nace en la orilla occidental del Mediterráneo en idénticas condiciones al primero. Responsable en parte de ese conflicto es la antigua colonia focense de Marsella. Los romanos habían depositado en el Tesoro de Marsella el ex voto enviado a Delfos con motivo de la victoria ante Veyes el 304 a. C., y es posible que ya desde entonces hubieran concluido una alianza ${ }^{46}$. También habían facilitado el comercio de Marsella con Italia al pacificar las costas etruscas y ligures, y esta comunidad de intereses había conducido el 236 a. C. a nuevas alianzas. En España, Marsella comerciaba mediante el intermedio de una serie de delegaciones igualmente fundadas por los griegos. A través de su intermediario, Roma entra en contacto con estos últimos, protegiéndoles contra Cartago, cuyos dominios se remontaban por la costa española desde el sur, compensando así la pérdida de las posesiones que se habría visto obligada a ceder en el Mediterráneo oriental. Sagunto solo serviría de casus belli para este segundo conflicto.

XI. Después de la victoria de Escipión en Zama el 201 a. C., Roma se instala en España, en la cual, el 197 a. C. crea dos provincias. Sin embargo, le sigue cediendo a Marsella, durante cerca de un siglo, la responsabilidad de garantizar la seguridad de sus relaciones con esta parte de sus territorios ${ }^{47}$.

${ }^{43}$ Laffi, U., Il sistema di alleanze itálico, en Storia di Roma, II,I: La repubblica imperiale (Torino, Einaudi, 1990), pp. 285-304. 79-90.ra annibalica, , -1990), pp. 19-

${ }^{44}$ Liv. IX,43,26.

${ }^{45}$ POLYB. I, 17,3; véase GABBA, E., La prima guerra púnica e gli inizi dell espansione transmarina, en Storia di Roma, II, I, La repubblica imperiale (Torino, Einaudi, 1990), pp. 55-67

${ }^{46}$ Just., Epit., XLIII,5. Sobre Marsella y sus relaciones con Roma: BuONO-CORE, R., Roma, Marsella y el mediterráneo occidental, en Semanas de Estudios Romanos (Valparaíso 1991), VI, pp. 21-34; NeNCI, G., Le relazioni con Marsiglia nella politica estera romana, en Rivista di Studi Liguri, 24 (1958), pp. 24-97.

${ }^{47}$ Clemente, G., La guerra annibalica, en Storia di Roma, II,I: La repubblica imperiale (Torino, Einaudi, 1990), pp. 79-90. 
Otros ejemplos demuestran ${ }^{48}$ que la instalación de una colonia en Narbona el 118 a. C., no significó la creación de una provincia en el golfo de León; tampoco existe ni gobierno ni ejército cuando los cimbros amenazaron la Provenza, territorio en el que Roma se instalará solo después de la victoria de Mario. Se señala ${ }^{49}$ que si Yugurta disfrutó durante mucho tiempo de idéntica confianza, es porque era el cliente de toda la ciudad, así como los aristócratas que la dirigían; la práctica de la clientela les cegó mucho más que la corrupción de cuya práctica los acusa Salustio. Semejante actitud explica las dudas, la prudencia o la paciencia, que con frecuencia son causa de asombro en la historia romana, como también el incesante replanteamiento de las mismas características: es el caso de las expediciones en Iliria, o las guerras de Macedonia contra Mitrídates.

Estos replanteamientos se manifiestan en Oriente con igual intensidad que en Occidente. Después de intervenir en la costa occidental del Adriático, el 229 a. C. Roma repatria sus tropas, mientras que por otro lado no cesa de anexarse tierras en Italia; la vigilancia de las costas ilirias se la habían confiado a un príncipe local, Demetrio de Faros, controlándole mediante los lazos del sistema de clientela. En el año 220 a. C., Roma revela el verdadero significado de esta situación al atacarle en el instante en que empieza a mostrarse demasiado despreocupado de los intereses de su protectora ${ }^{50}$.

XII. El 196 a. C., después de su victoria sobre Filipo, durante la segunda guerra macedónica, Flaminio proclama la libertad de las ciudades griegas; al año siguiente, conduce a la mayoría contra el rey de Esparta, Nabis, que practicaba una peligrosa política social con sus vecinos, con el ejemplo que daba a sus clases más desfavorecidas ${ }^{51}$. El 190 a. C., Escipión el Africano acompaña a su hermano, el cónsul Lucio Escipión, en una expedición contra Antíoco, especialmente temido por Roma desde que Aníbal se encontraba en sus costas desde hace 5 años. El vencedor de Cartago propone una política de negociaciones y de alianzas, como pretexto de la clemencia que le habría permitido asociarse con pueblos ibéricos contra los cartagineses, mientras que sus adversarios en Roma le acusan de haberse dejado comprar por el rey. Después de la victoria de Pydna, Roma se sigue contentando con reemplazar el reino de Macedonia con cuatro repúblicas aliadas. Habría de ser necesario que se dejasen atrapar con los engaños de Andrónico, que pretendía hacerse pasar por el hijo de Perseo, el derrotado en Pydna, con el fin de crear el 148 a. C. la provincia de Macedonia.

XIII. Entonces podemos ver que cada vez que le era posible, Roma cambiaba sus relaciones con el exterior a un sistema de clientela, base de la vida social y de la actividad política de la aristocracia que la dirigía; además, aplicaba el sistema

\footnotetext{
${ }^{48}$ Badian, E., Notes on provincia Gallia in the late Republic, en Mélanges darchéologie et d histoire offerts à A. Piganiol (Paris, 1966), II, pp. 901-903.

${ }^{49}$ BADIAN, E., Roman Imperialism in the Late Republic (Oxford, 1968), p. 25.

${ }^{50}$ GABBA, E., L'Imperialismo romano, en Storia di Roma, II,I: La repubblica imperiale (Torino, Einaudi, 1990), pp. 189-233.

${ }^{51}$ Liv. XXXIV,31,11.
} 
con el mismo espíritu y siguiendo los mismos principios resumidos en el concepto de fides que presidía las relaciones entre los ciudadanos.

A esto cabría añadir los innumerables lazos que consolidaban los romanos más influyentes gracias a su actividad personal o a las magistraturas en las que se desempeñaban con colectividades o individuos no romanos. Las ocasiones más idóneas suelen ser en el curso de las embajadas enviadas o diversas orientaciones recibidas de los Estados griegos después de la Segunda Guerra Púnica.

En el 343 a. C. no es Capua la que se entrega a Roma, sino su aristocracia reclamando ayuda romana contra la plebe de la Campania compuesta en gran parte por samnitas, que poco a poco se habían infiltrado en las ciudades, agitándose con la cercanía de las bandas que llegaban de las montañas. Sin embargo, tanto en el Senado como en los comicios se manejó la masa de votantes de manera que prefirieran esta alianza a la que ya unía a Roma con los samnitas, hablando de una deditio en toda regla, lo cual comprometía la buena fe del Estado.

Independiente de la función diplomática de la paz, no se puede ocultar la realidad de que la relación de fuerzas es claramente desfavorable a Roma, probablemente más allá de lo que nuestras fuentes nos informan, lo que por cierto, le da un carácter más bien defensivo, lo que no impide que al mismo tiempo sea también creativa.

Por otra parte las imprecisiones del vocabulario diplomático, incluso en fuentes como Tito Livio; las dilaciones en la toma de decisiones; las fallas o la precariedad de algunos enfoques, se constituyen en los elementos que demuestran las limitaciones del uso de la paz, sobre todo, desde el punto de vista político e ideológico.

Es probablemente en esta función que la diplomacia del siglo $V$, aún bastante arcaica, nos muestra sus limitaciones, a pesar de una tradición un tanto artesanal, que nos impide ignorar todas esas realidades.

Sin embargo, está bien documentado en este siglo, que una de las principales motivaciones de las guerras es la búsqueda de un botín que resulta necesariamente más rentable si la victoria es irreversible.

El problema de la construcción y funcionamiento de la diplomacia romana, aunque se hayan escrito trabajos de un indudable valor, su conocimiento es aún parcial, por lo que sin lugar a dudas hay mucho por hacer antes que el problema quede históricamente resuelto.

BiBLIOGRAFÍA

Ampolo, C. y otros, Popoli e civiltà dell Italia antica (Roma, 1984), VIII.

Ampolo, C., La storiografia su Roma arcaica e i documenti, en Tria Corda. Studi in onore di Arnaldo Momigliano (Como, 1983).

Auliard, C., La diplomatie romaine. L'autre instrument de la conquête. De la fondation

à la fin des guerres samnites (753-290 av. J.-C.) (Rennes, 2006).

Badian, E., Foreign Clientelae (264-70 a. C.) (Oxford, 1958).

Badian, E., Notes on provincia Gallia in the late Republic, en Mélanges d archéologie et d histoire offerts à A. Piganiol (Paris, 1966), II.

BADIAN, E., Roman Imperialism in the Late Republic (Oxford, 1968).

BRISSON, J.-P., Problèmes de la guerre à Rome (Paris, 1969). 
Buono-Core, R., Diplomacia y monarquía. Rómulo y Numa, en REHJ., 25 (2013). Buono-Core, R., Roma, Marsella y el mediterráneo occidental, en Semanas de Estudios Romanos (Valparaíso 1991), VI.

Caire, E. - Pittia, S. (editores), Guerre et diplomatie romaines, IV-III siècles av. J.-C., pour un réexamen des sources (Aix-en-Provence, 2006).

Carandini, A., La nascità di Roma (Torino, 1997).

Cary, M. - Scullard, H. H., A History of Rome (London, McMillan, 1973; traducción al italiano, Bolonia, 1981), I.

Catalano, F., Linee del sistema sovranazionale romano (Torino, 1966), I.

Clemente, G., Dal territorio della città all egemonia in Italia, en Storia di Roma, II,1: La repubblica imperiale (Torino, Einaudi, 1990).

Clemente, G., Esperti ambasciatori del senato e la formazione della política estera romana tra il III e il II sec. A. C., en Athenaeum, N.S., 64 (1976).

Clemente, G., La guerra annibalica, en Storia di Roma, II,I: La repubblica imperiale (Torino, Einaudi, 1990).

Cornell, T. J., The Formation of the Historical Tradition of Early Rome, en Moxon, I. - Smart, J. D. - Woodman, A. J. (editores), Past perspectives: Studies in Greek and Roman Historical Writing (Cambridge, 1986).

CORNELl, T., Alcune riflessioni sulla formazione della tradizione storiografica su Roma arcaica, en Roma arcaica e le resenti scoperte archeologique. Giornate di studio in onore di U. Coli. Firenze, 29-30 Maggio 1979 (Milano, 1980).

De Francisci, P., Primordia civitatis (Roma, 1959).

De Francisci, P., Variación su tempi di Prehistoria Romana (Roma, 1974).

De Martino, F., Storia della costituzione Romana (Napoli, 1964), II.

EcksteIn, A. M., Mediterranean Anarchy, Interstate War, and the Rise of Rome (Berkeley - Los Angeles - London, University of California Press, 2006).

EILers, C. (editor), Diplomats and Diplomacy in the Roman World (Leiden - Boston, Brill, 2009).

Frézouls, Ed. - Jacquemin, A. (editores), Les relations internationales. Actes du Colloque de Strasbourg 15-17 juin 1993 (París, De Boccard, 1995).

GabBA, E., Ancora sulle origini di Roma, en Athenaeum, 89 (2001).

GABBA, E., Considerazione sulla tradizione letteraria sulle origini della repubblica, en Les origines de la République Romaine, Entretiens Hardt, XIII (Genève, 1967).

GabBa, E., L'Imperialismo romano, en Storia di Roma, II,I: La repubblica imperiale (Torino, Einaudi, 1990).

GABBA, E., La prima guerra púnica e gli inizi dell espansione transmarina, en Storia di Roma, II, I, La repubblica imperiale (Torino, Einaudi, 1990).

GrandazZI, A., La fondation de Rome (Paris, 1991).

HaRris, W. V., War and Imperialism in Republican Rome 327-70 B.C. (Oxford, 1979; traducción al castellano, Madrid, 1989).

Herrera, H., Res privata, res publica, imperium, en Semanas de Estudios Romanos (Valparaíso, 1977), I.

Heurgon, J., La guerre romaine aux IV-III siècles et la "fides romana", en Problèmes de la guerre à Rome (Paris, 1969).

LAFFI, U., Colonie e municipi nello Stato romano (Roma, 2007).

LAFF, U., Il sistema di alleanze itálico, en Storia di Roma, II,I: La repubblica imperiale (Torino, Einaudi, 1990).

LETTA, C., La tradizione storiografica sull età regia: Origine e valore, en Alle Origini di 
Roma. Atti del Colloquio tenuto a Pisa il 18 e 19 settembre 1987 (Pisa, Giardini, 1988).

NencI, G., Le relazioni con Marsiglia nella politica estera romana, en Rivista di Studi Liguri, 24 (1958).

Nicolson, H., Diplomacy (London, Oxford University Press, 1939; traducción al castellano, México, Fondo de Cultura Económica, 1948).

POUCET, J., Les origines de Rome (Bruxelles, 1985).

Poucet, J., Les Rois de Rome Tradition et histoire (Bruxelles, 2000). 
